\title{
High-speed solar wind streams and polar mesosphere winter echoes at Troll, Antarctica
}

\author{
S. Kirkwood ${ }^{1}$, A. Osepian ${ }^{2}$, E. Belova ${ }^{1}$, and Y.-S. Lee ${ }^{3}$ \\ ${ }^{1}$ Polar Atmospheric Research, Swedish Institute of Space Physics, P.O. Box 812, 98128 Kiruna, Sweden \\ ${ }^{2}$ Polar Geophysical Institute, Halturina 15, 183023 Murmansk, Russia \\ ${ }^{3}$ Korea Astronomy and Space Science Institute, 776 Daedeokdae-ro, Daejeon, South Korea \\ Correspondence to: S. Kirkwood (sheila.kirkwood@irf.se)
}

Received: 31 October 2014 - Revised: 28 April 2015 - Accepted: 30 April 2015 - Published: 1 June 2015

\begin{abstract}
A small, $54 \mathrm{MHz}$ wind-profiler radar, MARA, was operated at Troll, Antarctica $\left(72^{\circ} \mathrm{S}, 2.5^{\circ} \mathrm{E}\right)$, continuously from November 2011 to January 2014, covering two complete Antarctic winters. Despite very low power, MARA observed echoes from heights of 55-80 km (polar mesosphere winter echoes, PMWE) on $60 \%$ of all winter days (from March to October). This contrasts with previous reports from radars at high northern latitudes, where PWME have been reported only by very high power radars or during rare periods of unusually high electron density at PMWE heights, such as during solar proton events. Analysis shows that PWME at Troll were not related to solar proton events but were often closely related to the arrival of high-speed solar wind streams (HSS) at the Earth, with PWME appearing at heights as low as $56 \mathrm{~km}$ and persisting for up to 15 days following HSS arrival. This demonstrates that HSS effects penetrate directly to below $60 \mathrm{~km}$ height in the polar atmosphere. Using local observations of cosmic-noise absorption (CNA), a theoretical ionization/ion-chemistry model and a statistical model of precipitating energetic electrons associated with HSS, the electron density conditions during the HSS events are estimated. We find that PMWE detectability cannot be explained by these variations in electron density and molecularion chemistry alone. PWME become detectable at different thresholds depending on solar illumination and height. In darkness, PWME are detected only when the modelled electron density is above a threshold of about $1000 \mathrm{~cm}^{-3}$, and only above $75 \mathrm{~km}$ height, where negative ions are few. In daylight, the electron density threshold falls by at least 2 orders of magnitude and PWME are found primarily below $75 \mathrm{~km}$ height, even in conditions when a large proportion of nega-
\end{abstract}

tive ions is expected. There is also a strong dawn-dusk asymmetry with PWME detected very rarely during morning twilight but often during evening twilight. This behaviour cannot be explained if PMWE are caused by small-scale structure in the neutral/molecular-ion gas alone but may be explained by the presence of charged meteoric dust.

Keywords. Ionosphere (Particle acceleration)

\section{Introduction}

Polar mesosphere winter echoes (PWME) are VHF radar echoes from layered structures at heights $50-90 \mathrm{~km}$ during the winter months at high latitudes. They have previously been reported from several locations at high northern latitudes $\left(65-70^{\circ} \mathrm{N}\right)$, including Poker Flat, Alaska (e.g. Ecklund and Balsley, 1981), Kiruna, Sweden (e.g. Kirkwood et al., 2002), and Andenes, Norway (e.g. Zeller et al., 2006), as well as from Davis in Antarctica, at $69^{\circ} \mathrm{S}$ (Morris et al., 2011). They are most of the time rather weak and visible regularly only to very high power VHF radars such as the former Poker Flat $50 \mathrm{MHz}$ radar or the new MAARSY radar in Andenes (e.g. Rapp et al., 2011). For less powerful radars they become visible during periods of unusually high electron density at PMWE heights, such as during solar proton events (e.g. Kirkwood et al., 2002). Their morphology often suggests that they descend following gravity-wave phase lines (e.g. Belova et al., 2005; Rapp et al., 2011), so that wind shear is likely involved. While some studies have suggested that they may be explained simply by layered turbulence, induced by wind shear, in the neutral atmosphere (e.g. 
Lübken et al., 2006), others have suggested that at least the strongest echoes can only be explained by additional factors such as plasma waves driven by partial reflection of infrasound (Kirkwood et al., 2006) or the presence of charged dust layers (e.g. Stebel et al., 2004; Rapp et al., 2011). In particular, recent experiments using active modification of PWME by RF heating have given support for the involvement of charged dust (e.g. Belova et al., 2008; La Hoz and Havnes, 2008).

The $54 \mathrm{MHz}$ Moveable Atmospheric Radar for Antarctica (MARA) started operation at the Swedish/Finnish Antarctic stations Wasa/Aboa in 2007 (Kirkwood et al., 2007). At this location, measurements could be made only during the austral summer when the very strong polar mesosphere summer echoes (PMSE) can be observed (e.g. Kirkwood et al., 2013). MARA was moved to the year-round station Troll $\left(72^{\circ} \mathrm{S}, 2.5^{\circ} \mathrm{E}\right.$; geomagnetic latitude $\left.63^{\circ} \mathrm{S}\right)$ in November 2011, where it operated continuously until January 2014 (when it was again moved, to Maitri Station, Antarctica). The power-aperture product of MARA is about 20 times less than the VHF radar in Kiruna and at least 200 times less than MAARSY, so it was very surprising that frequent PWME were detected by MARA during the austral winters of 2012 and 2013, despite the fact that no major solar proton events occurred during that time.

Here we make a careful analysis of the Troll PWME to try to determine why they were observed so frequently, and whether their characteristics can shed light on the nature of the processes which make them detectable by radar. In particular we examine the relationship with high-speed solar wind streams (HSS) since these have recently been shown to have a strong influence on VHF radar echoes during some summer periods (Lee et al., 2013, 2014). High-energy electron precipitation associated with the arrival of HSS at the Earth has been well documented and is expected to lead to significant ionization at PMWE heights at the location of Troll (e.g. Meredith et al., 2011).

\section{PMWE observations}

MARA is a relatively small wind-profiler radar operating at $54.5 \mathrm{MHz}$. The configuration deployed at Troll used a transmitter providing $20 \mathrm{~kW}$ peak pulse power, six receivers, three antenna groups (each $4 \times 4$ dipole antennas) with both transmission and reception and three antenna groups (each $2 \times 2$ Yagi antennas) for reception only. During the winter months, the radar operated a sequence of three operating modes, usually 1 min per mode - two for tropospheric profiles and one covering the mesosphere. The mesospheric mode (named fca4500) uses an 8 bit, $600 \mathrm{~m}$ baud, complementary code. The radar repeats the coded-pulse transmission at a rate of $1300 \mathrm{~Hz}$ and records the scattered signal over the height interval $5-100 \mathrm{~km}$, with $600 \mathrm{~m}$ resolution, following each transmission. For the purpose of the present study,
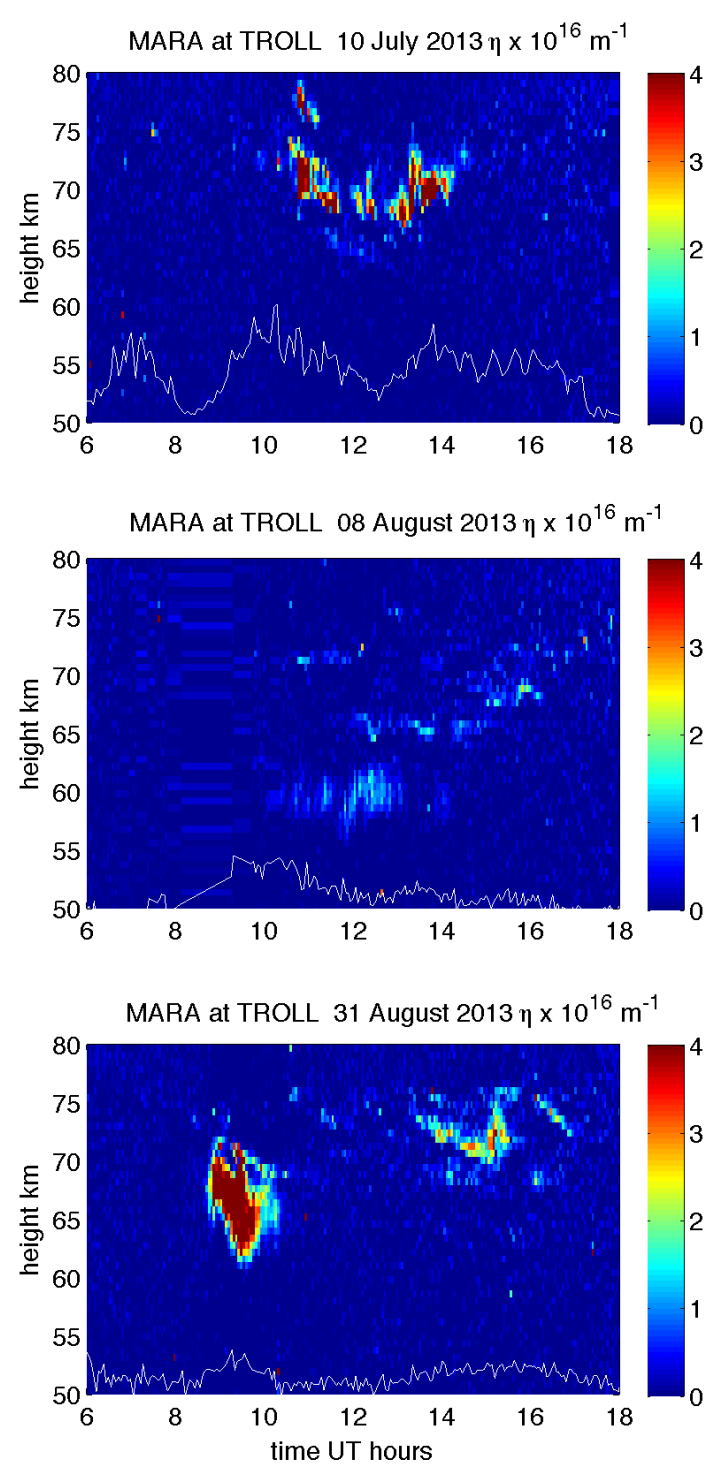

Figure 1. Examples of PWME observed by MARA at Troll, Antarctica, during austral winter 2013. Colour scale shows volume reflectivity in units of $10^{-16} \mathrm{~m}^{-1}$. The white line at the bottom of each panel shows cosmic-noise absorbtion (CNA) at $54.5 \mathrm{MHz}$, where $5 \mathrm{~km}$ on the height scale corresponds to $1 \mathrm{~dB}$ CNA.

scattered signals from 256 consecutive pulses, together with background noise, are integrated coherently to increase the signal-to-noise ratio. Coherently averaged height profiles of received power are then averaged over $1 \mathrm{~min}$, and the measurement is repeated every $3 \mathrm{~min}$. Signal volume reflectivities $(\eta)$, which are the proportion of the incident signal which is scattered back to the radar for each metre of distance through the atmosphere, are calculated by subtracting the background noise (minimum power received) and scaling the remaining signal power according to the distance between the radar and the echo, and the radar characteristics, using the radar calibration. Calibration is made continuously using 

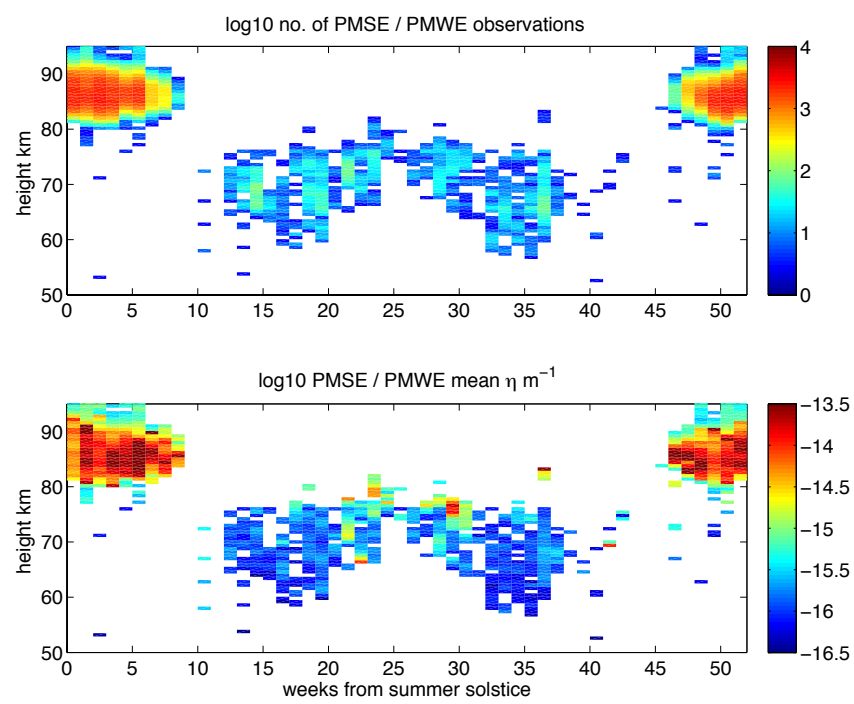

Figure 2. Upper panel: $\log _{10}$ of the number of observations per week of PMWE and PMSE (observations made every $3 \mathrm{~min}$ ). Lower panel: average volume reflectivity $\left(\log _{10} \mathrm{~m}^{-1}\right)$ in detected echoes (detection threshold $3 \times 10^{-17} \mathrm{~m}^{-1}$ ). Observations by MARA at Troll, Antarctica, during the 2-year period 10 January 2012-10 January 2014 as a function of height and time of year (time resolution 1 week).

the daily variation of the galactic noise signal, with checks against radiosondes when available (1-6 each summer season). For more details of the calibration see Kirkwood et al. $(2010,2007)$. The accuracy in $\eta$ due to the calibration is estimated to be $20 \%$ (Kirkwood et al., 2010). The precision which results from random uncertainties in received power is about $5 \%$ for $\eta>3 \times 10^{-16} \mathrm{~m}^{-1}$, increasing to $25 \%$ for $\eta=3 \times 10^{-17} \mathrm{~m}^{-1}$.

Figure 1 shows examples of PWME from the measurements at Troll - typically seen in the form of slowly descending layers in the hours around noon, occasionally in the form of a more extended "cloud". Note that PWME are typically very weak - often only just above the background noise level for this radar. Statistics of the PWME have been made for the whole 2-year period using a detection threshold of $\eta=3 \times 10^{-17} \mathrm{~m}^{-1}$, which corresponds to a signalto-noise ratio of about $10 \%$. To avoid false detections due to sporadic meteors or radio interference, we have required that this threshold be exceeded at the same height during at least two measurements before and after the time a detection is recorded. PWME were detected on 272 out of the 453 days between March and October when radar observations were made ( $60 \%$ of days). Figure 2 summarizes the observations of mesospheric radar-echo layers during the 2 years at Troll, including both PMSE, at heights above $80 \mathrm{~km}$ during the weeks closest to summer solstice, and PWME, primarily during winter at heights below $80 \mathrm{~km}$ (although there are also a few occurrences of echoes at the lower heights in summer). The upper plot shows the logarithm of the num-

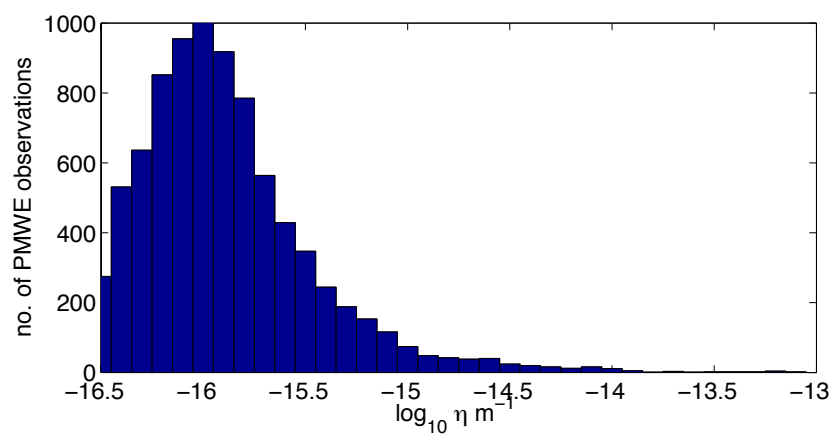

Figure 3. Distribution of PMWE volume reflectivities.

ber of PWME/PMSE detected at each height, during each week of the year, in the 2-year data set, which has $3 \mathrm{~min}$ time resolution (100\% occurrence would give 6720 detections per week). The lower plot shows the mean volume reflectivity in the detected echoes. It is clear in Fig. 2 that PWME are much weaker, and detected much less frequently, than PMSE, with the differences in both average volume reflectivities and occurrence rates being about 2 orders of magnitude. PMWE volume reflectivities for the 2 years at Troll are further illustrated in Fig. 3. Values for PWME are mainly in the range $10^{-16}$ (median) to $10^{-15} \mathrm{~m}^{-1}$, with a few at $10^{-14}-10^{-13} \mathrm{~m}^{-1}$, which can be compared to typical values for PMSE at Troll, which are $10^{-15}$ (median) to $10^{-12} \mathrm{~m}^{-1}$ (maximum) (see e.g. Kirkwood et al., 2013).

A particularly noticeable feature of PWME is the short interval each day when they are detected - below $75 \mathrm{~km}$ height they are confined to a few hours around noon (whereas PMSE are observed $24 \mathrm{~h}$ a day). This is apparent in all of the examples in Fig. 1, which show PWME concentrated in the hours around noon and is further illustrated in Fig. 4a, which shows occurrence rates for all of our Troll PWME as a function of solar zenith angle - very few echoes are detected at solar zenith angles larger than $98^{\circ}$, i.e. in darkness. Such large solar zenith angles occur only for a short period around midnight at the beginning and end of the PMWE season but for up to $22 \mathrm{~h}$ a day in mid-winter. The background electron density at PMWE heights (the ionospheric D region) also strongly depends on the solar zenith angle. Even though several ionization sources affect the night-time D region (hydrogen nightglow, energetic electrons and protons, cosmic rays), they do not lead to as high electron densities as they would during daytime as the electrons attach to neutral molecules (e.g. $\mathrm{O}_{2}, \mathrm{O}_{3}, \mathrm{CO}_{2}$ ) to form negative ions. During daytime, attached electrons are efficiently detached by the photoelectric effect and by the high daytime concentration of atomic oxygen (see e.g. Torkar and Friedrich, 1983). Whether this day-night variation in electron density and ion composition is enough to explain the day-night variation in PWME is considered in the next section.

PWME have often been reported in association with solar proton events, or during conditions of high geomagnetic 

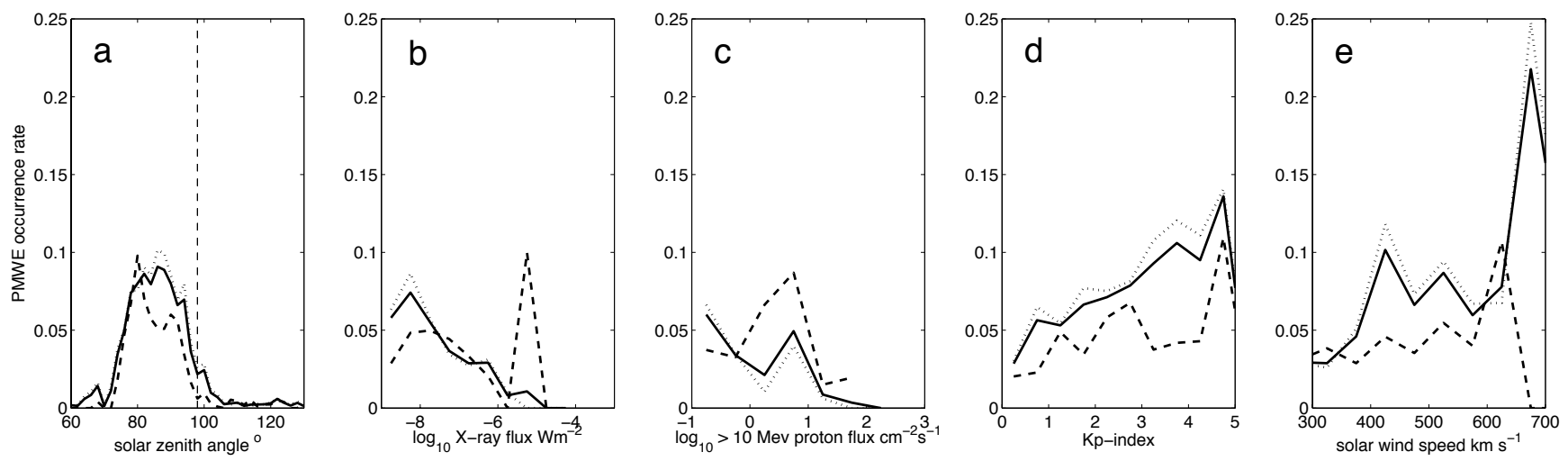

Figure 4. PMWE occurrence rates for the months March-October, at any height below $75 \mathrm{~km}$, as a function of (a) solar zenith angle, (b) solar X-ray flux, (c) solar proton flux, (d) Kp index and (e) solar wind speed. For (b-e), only observations for solar zenith angle less than $98^{\circ}$ are considered. The dashed line is for the year 2012, the dotted line for 2013 and the solid line for both together. Occurrence rates are calculated as the number of times during which PWME were observed divided by the number of observations which were made (one observation each $3 \mathrm{~min}$ ).

disturbance as represented by the Kp index, and it has been generally concluded that their detectability is determined by increased electron density associated with these conditions. It should be remembered that $\mathrm{Kp}$ is not a cause but rather a symptom of disturbances which can lead to enhanced electron densities in the ionospheric $\mathrm{E}$ region (above $100 \mathrm{~km}$ height, where electric currents flow causing magnetic fluctuations which affect the Kp index). Since PWME occur at much lower heights than the E-region currents, $\mathrm{Kp}$ is not necessarily a good indicator of enhanced electron density at PMWE heights. To try to find the cause of enhanced PMWE detection, we have examined the occurrence rate of PWME depending on the levels of three different parameters which are known to affect electron density at PMWE heights - solar protons, solar wind speed, solar X-rays and the Kp index. Solar protons and solar X-rays directly cause ionization at PMWE heights, and high solar wind speeds are often associated with HSS, which are known to cause precipitation of high-energy electrons from within the magnetosphere and cause ionization at PMWE heights (e.g. Tsurutani et al., 2006; Meredith et al., 2011; Kavanagh et al., 2012). To compare with PWME, we here take solar wind, solar proton fluxes and $\mathrm{Kp}$ index from the OMNI 2 data set (http: //omniweb.gsfc.nasa.gov/) and X-ray fluxes from the GOES database (http://www.swpc.noaa.gov/Data/goes.html).

Figure $4 \mathrm{~b}-\mathrm{e}$ show occurrence rates as a function of solar X-ray flux, solar proton flux, $\mathrm{Kp}$ index and solar wind speed, respectively. Occurrence rates in Fig. $4 \mathrm{~b}-\mathrm{e}$ are the number of times when PWME were observed (during daylight, solar zenith angles $<98^{\circ}$, at any height) divided by the number of daylight observations which were made (during the months March-October). To give an indication of the uncertainties, occurrence rates have been calculated for the whole 2-year period (solid lines) and separately for 2012 (dashed lines) and 2013 (dotted lines). There is a clear de- pendence on $\mathrm{Kp}$ and on solar wind speed, but not on solar X-ray or proton flux, although the variability between the 2 years is high. This can be considered further by reference to Table 1, which shows day-to-day occurrence rates of PWME as a function of whether or not each of the parameters was enhanced. The levels which are considered enhanced are $\mathrm{Kp}>2$, solar wind speed $>450 \mathrm{~km} \mathrm{~s}^{-1}$, solar proton fluxes above $1 \mathrm{~cm}^{-2} \mathrm{sr}^{-1} \mathrm{~s}^{-1}$ (>10 MeV protons) and solar X-ray flux $>5 \times 10^{-7} \mathrm{Wm}^{-2}(0.5-4.0 \AA \mathrm{X}$-rays $)$. The parameter is considered enhanced if it exceeded the threshold at any time during the day (during daylight only for X-ray fluxes), and a PMWE is considered present if it was detected at any time during the day. Here we can see that most days when PWME were detected coincided with either enhanced Kp or enhanced solar wind, or both (rows 5-16). Very few days (13) with detected PWME occurred when only X-rays or protons were enhanced (rows 2-4). By far the majority of days with detected PWME, 204 days out of 272, occurred when neither solar protons nor solar X-rays were enhanced (rows 1, 5, 9 and 13). Thus it is clear that most PWME at Troll during 2012 and 2013 are not related to solar protons or solar Xrays but instead to some other source of disturbance. PMWE occurrence rates are shown in the last column of Table 1, in bold type for conditions represented by more than 10 days of observations - occurrence rates based on fewer days are likely not representative. The highest occurrence rates are associated with enhanced solar wind speeds, without enhanced proton or X-ray fluxes and both with and without enhanced Kp (76 and $77 \%$, rows 5 and 13). These categories include 108 days of PMWE observations, and the high occurrence rates indicate that HSS are a likely source of PMWE enhancement during at least this number of days. For days with no indication of disturbance in terms of the indices in Table 1 (row 1), the PMWE occurrence rate is $44 \%$. This is significantly lower than during conditions of high-speed solar wind, 
Table 1. Distribution of observation days and days with PMWE detection as a function of the disturbance level each day, as represented by Kp index, solar wind speed (Vsw), solar proton flux (pf) and solar X-ray flux (Xf). Each day is categorized into 1 of 16 possible states according to whether the threshold value for each parameter is exceeded at some time during the day. Thresholds are $\mathrm{Kp}>2$, Vsw $>450 \mathrm{~km} \mathrm{~s}^{-1}$, pf $>1 \mathrm{~cm}^{-2} \mathrm{sr}^{-1} \mathrm{~s}^{-1}$ (for $>10 \mathrm{MeV}$ protons ) and $\mathrm{Xf}>5 \times 10^{-7} \mathrm{Wm}^{-2}$ (for $0.5-4.0 \AA \mathrm{X}$-rays, only daytime considered). Ones in columns 2-5 indicate that the threshold for the corresponding parameter was exceeded. Column 6 shows the number of days in each category when observations were made, and column 7 shows the number of those days when PWME were detected. PMWE occurrence rates in the final column are the number of days with PWME divided by the number of observation days on each row. These are shown in bold type when the number of observation days is more than 10 .

\begin{tabular}{lrrrrrrr}
\hline $\begin{array}{l}\text { Row } \\
\text { no. }\end{array}$ & $\begin{array}{r}\text { Kp } \\
>2\end{array}$ & $\begin{array}{r}\text { Vsw } \\
>450\end{array}$ & $\begin{array}{r}\text { pf } \\
>1\end{array}$ & $\begin{array}{r}\text { Xf } \\
>5\end{array}$ & $\begin{array}{r}\text { Observation } \\
\text { days }\end{array}$ & $\begin{array}{r}\text { PMWE } \\
\text { days }\end{array}$ & $\begin{array}{r}\text { PMWE occ. } \\
\text { rate \% }\end{array}$ \\
\hline 1 & 0 & 0 & 0 & 0 & 91 & 40 & $\mathbf{4 4}$ \\
2 & 0 & 0 & 0 & 1 & 19 & 7 & $\mathbf{3 7}$ \\
3 & 0 & 0 & 1 & 0 & 8 & 5 & 63 \\
4 & 0 & 0 & 1 & 1 & 3 & 1 & 33 \\
5 & 0 & 1 & 0 & 0 & 17 & 13 & $\mathbf{7 6}$ \\
6 & 0 & 1 & 0 & 1 & 2 & 1 & 50 \\
7 & 0 & 1 & 1 & 0 & 2 & 0 & 0 \\
8 & 0 & 1 & 1 & 1 & 1 & 1 & 100 \\
9 & 1 & 0 & 0 & 0 & 93 & 56 & $\mathbf{6 0}$ \\
10 & 1 & 0 & 0 & 1 & 16 & 10 & $\mathbf{6 3}$ \\
11 & 1 & 0 & 1 & 0 & 18 & 11 & $\mathbf{6 1}$ \\
12 & 1 & 0 & 1 & 1 & 7 & 3 & 43 \\
13 & 1 & 1 & 0 & 0 & 123 & 95 & $\mathbf{7 7}$ \\
14 & 1 & 1 & 0 & 1 & 23 & 9 & $\mathbf{3 9}$ \\
15 & 1 & 1 & 1 & 0 & 24 & 16 & $\mathbf{6 7}$ \\
16 & 1 & 1 & 1 & 1 & 6 & 4 & 67 \\
\hline
\end{tabular}

but is far from zero. Some source of disturbance at PMWE altitudes, which is not represented by the indices in Table 1, must have occurred almost half of the time.

Energetic electron precipitation during HSS has been studied statistically using satellite measurements by Meredith et al. (2011). Precipitation starts abruptly as the solar wind speed increases sharply from below 400 to above $450 \mathrm{~km} \mathrm{~s}^{-1}$ as the HSS arrives at the Earth, and remains elevated over at least 8 days. This gives us the possibility to examine the PMWE-HSS relation further using the superposed epoch method. The sources of HSS on the Sun are coronal holes these are independent of the sources of solar X-rays and solar protons which may or may not be present at the same time. Coronal holes rotate with the Sun and can cause repeating HSS at 27-day intervals. During 2012 and 2013, however, there was generally more than one coronal hole present on the Sun and the interval between HSS was much less. Altogether about 24 HSS arrivals (abrupt increases in solar wind speed) could be found during our observation period, but not all are suitable because of overlap with other kinds of disturbance or too soon arrival after a previous HSS. We have identified 12 occasions during the 2012 and 2013 austral winter when distinct HSS arrived at the Earth (solar wind speed in-
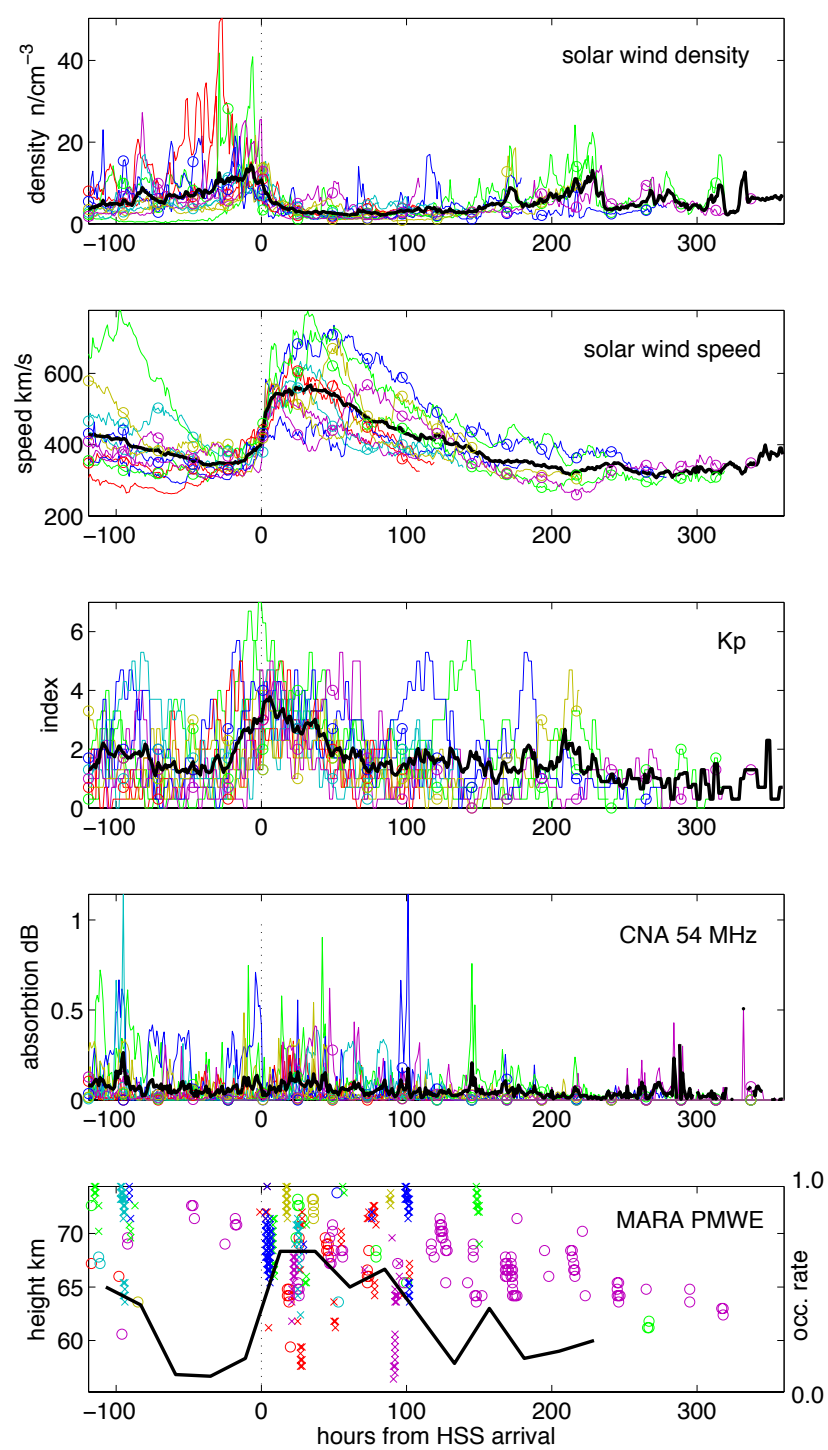

Figure 5. Superposed measurements for 12 high-speed solar wind streams, aligned at the time of onset (defined by the solar wind speed increasing through $450 \mathrm{~km} \mathrm{~s}^{-1}$ ) and covering the period from 5 days before to 15 days after the onset. Time series are truncated if a new high-speed stream or enhanced solar proton fluxes arrive. First panel: hydrogen density in the solar wind; second panel: solar wind speed; third panel: geomagnetic Kp index; fourth panel: CNA at $54 \mathrm{MHz}$ measured using MARA receivers; fifth panel: heights and times of PMWE detections using MARA (coloured symbols and left-hand axis) and the fraction of the events when PWME were observed each $24 \mathrm{~h}$ (black line, right-hand axis). Different colours and symbols $(\mathrm{X}, \mathrm{O})$ indicate the different events; see Table 2. Black curves show averages over all events.

creased abruptly from below 400 to more than $450 \mathrm{~km} \mathrm{~s}^{-1}$ ); no other HSS arrived and there were no elevated proton or X-ray fluxes for at least 4 days before and after the HSS arrival. These are listed in Table 2, together with the number of hours after the arrival before any other disturbance arrived. 
Table 2. Dates and times of onset for HSS events used in Figs. 5, 9, 10 and 11 . The number of hours after HSS onset which have been used in the analysis is given in the second column. The third column shows the corresponding line colour and symbol used in Fig. 5.

\begin{tabular}{lll}
\hline HSS event start & Time extent & Colour \\
\hline 12 Apr 2012 15:00 UT & $110 \mathrm{~h}$ & red O \\
24 Apr 2012 10:00 UT & $320 \mathrm{~h}$ & green O \\
04 Jun 2012 09:00 UT & $280 \mathrm{~h}$ & dark-blue O \\
19 Aug 2012 08:00 UT & $120 \mathrm{~h}$ & light-blue O \\
25 Aug 2012 02:00 UT & $220 \mathrm{~h}$ & yellow O \\
27 Mar 2013 10:00 UT & $360 \mathrm{~h}$ & magenta O \\
25 Apr 2013 10:00 UT & $120 \mathrm{~h}$ & red X \\
01 Jun 2013 06:00 UT & $240 \mathrm{~h}$ & green X \\
10 Jul 2013 08:00 UT & $180 \mathrm{~h}$ & dark-blue X \\
18 Jul 2013 12:00 UT & $140 \mathrm{~h}$ & light-blue X \\
25 Jul 2013 22:00 UT & $140 \mathrm{~h}$ & yellow X \\
04 Aug 2013 17:00 UT & $110 \mathrm{~h}$ & magenta X \\
\hline
\end{tabular}

In Fig. 5, for each event, we have plotted solar wind density, solar wind speed, Kp index, cosmic-noise absorption (CNA see next section) and PMWE observations from 5 days before the HSS arrival and up to 15 days afterwards (the time series are truncated when a new disturbance arrives). The PMWE occurrence rate curve superimposed on the lowest panel is the number of events with PWME detected each day divided by the number of events when observations were made (truncated when the number of undisturbed events drops below four). There is a clear lack of PWME in the days before the HSS arrival, particularly below $70 \mathrm{~km}$ altitude, followed by an abrupt increase at the HSS arrival, with PWME at all heights from 56 to $75 \mathrm{~km}$ in the first 4 days, and with PWME between 60 and $70 \mathrm{~km}$ continuing for up to 15 days. This can be compared with the behaviour of the Kp index, which starts to increase before the HSS arrival, and decreases again within 5 days to pre-HSS levels. Also, the solar wind speed itself falls to pre-HSS levels before the PMWE disappears. An obvious explanation is that Kp reacts most to the initial disturbance associated with the co-rotating interaction region of high solar wind density (Fig. 5, top panel) which arrives ahead of the HSS. The initial disturbance can include precipitation of auroral electrons (with energies of a few to a few tens of $\mathrm{keV}$ ), which will lead to increased conductivity and electric currents above $100 \mathrm{~km}$ altitude, affecting the Kp index. PWME below $70 \mathrm{~km}$ altitude are affected only by the higher-energy electron precipitation from the radiation belts $(>300 \mathrm{keV}$ ) which starts after the HSS onset (e.g. Meredith et al., 2011) and continues for several days afterwards.

\section{PMWE observations, modelled electron and negative-ion density}

The association of PWME with HSS provides a possibility to estimate the background electron density conditions and
Table 3. Characteristic energies for the exponential $\left(E_{1}\right)$ and powerlaw tail $\left(E_{2}\right)$ parts for the flux-energy distribution of energetic electrons (Eqs. 1 and 2) used to estimate electron density profiles. The three alternatives are fits to the mean ("HSS-mean"), upper-quartile ("HSS-UQ") and lower-quartile ("HSS-LQ") integral fluxes in the statistical study of electron precipitation during HSS by Meredith et al. (2011).

\begin{tabular}{lrr}
\hline Model & $E_{1} \mathrm{keV}$ & $E_{2} \mathrm{keV}$ \\
\hline HSS-mean & 39.4 & 4.36 \\
HSS-UQ & 19.9 & 3.70 \\
HSS-LQ & 21.9 & 2.27 \\
\hline
\end{tabular}

to examine whether PMWE detectability is affected only by electron density or also by some other process associated with daylight. To do this, we use energetic electron fluxes based on the statistical study by Meredith et al. (2011) to estimate the relative energy distribution of the incoming precipitating electron flux. This is used as input to a theoretical ionization/ion-chemistry model which is used to calculate electron and positive/negative-ion densities for a range of different total electron flux levels. Theoretical CNA from the model is then compared with measured CNA to estimate which flux level corresponds to a particular observation. A description of the ion chemistry included and the method of calculating ionization rates by energetic particles can be found in Kirkwood and Osepian (1995). The model uses the positive-ion scheme of Smirnova et al. (1988) (with four equivalent ions) and the negative-ion scheme of Torkar and Friedrich (1983) (two equivalent ions). The underlying neutral atmosphere model is MSIS00E (http://ccmc.gsfc.nasa. gov/modelweb/atmos/msise.html; Hedin, 1991). Ionization rates by energetic particles are calculated according to Rees (1963). For the present work, further UV ionization sources including nightglow have been added (following Kashirin, 1986). Note that the positive-ion chemistry and UV sources are the same as in the model described in Barabash et al. (2012).

The statistical study of Meredith et al. (e.g. 2011) provides integral fluxes for energies $>30,>100$ and $>300 \mathrm{keV}$. In order to estimate the relative flux-energy distribution, we have to assume some form of the flux-energy spectrum. Kirkwood et al. (2001) found that an exponential form fits well to fluxes during HSS-like conditions between 30 and $200 \mathrm{keV}$. Other authors (e.g. Rodger et al., 2013) have proposed a powerlaw form. Neither gives a close fit to the integral fluxes from Meredith et al. (e.g. 2011), so we fit a two-component spectrum with an exponential form below $100 \mathrm{keV}$ and a powerlaw form above that. The downward differential energy flux 
spectrum of the precipitating electrons has the form

$J=J_{\mathrm{o}} \exp \left(-E / E_{1}\right), \quad E<100 \mathrm{keV}$,

$J=A J_{\mathrm{o}} E^{-E_{2}}, \quad E>100 \mathrm{keV}$,

where $J$ is the downward flux, $E$ is electron energy in $\mathrm{keV}$, and $A$ is a constant which matches the two expressions at $E=100 \mathrm{keV}$. The values of $E_{1}$ and $E_{2}$ for fits to the mean (HSS-mean), lower-quartile (HSS-LQ) and upper-quartile (HSS-UQ) integral fluxes in Meredith et al. (2011) (first day after HSS onset, at $L=5$ ) are shown in Table 3. $J_{\mathrm{o}}$ is varied to achieve agreement with observed CNA. We here show results primarily using the HSS-mean form - calculations using the HSS-UQ and HSS-LQ forms have also been made and are used in estimating uncertainties in the results. Further description of the modelling can be found in Kirkwood et al. (2015), which employs the same ionization/ion-chemistry model used here, and the HSS-mean form, together with $J_{\mathrm{o}}$ corresponding to the integral fluxes in Meredith et al. (2011), to calculate the mean daily and seasonal variation in CNA which can be expected during HSS. Kirkwood et al. (2015) demonstrate good agreement with the mean HSS response observed by riometers (Kavanagh et al., 2012), which adds confidence for our use of this model.

Instantaneous and/or local precipitating electron fluxes can typically be an order of magnitude different from mean fluxes, so we cannot use mean fluxes for comparison with PWME. Fortunately, the MARA radar can also be used to measure CNA. Measurements of received power at times when no echoes from the transmitted signal are expected provide continuous monitoring of the cosmic-noise background (there is a small contribution from internal system noise, but this amount is known and can removed). The quietday cosmic-noise level is determined by binning 20 days of noise measurements into $10 \mathrm{~min}$ intervals of sidereal time. The undisturbed level is taken as the upper quartile in each bin, and is interpolated to the observation times. CNA is then the ratio of the quiet level to the instantaneous noise level. MARA has two separate antenna fields connected to separate receivers (one is used for reception only, and one for both transmission and reception). This allows for two independent estimates of CNA. Differences between simultaneous estimates have a mean of $0.00 \mathrm{~dB}$ and standard deviation of $0.10 \mathrm{~dB}$. This means that the standard deviations of estimates from each antenna field are $0.07 \mathrm{~dB}$. Examples of CNA measured by MARA are shown by the white lines superimposed on the lowest heights in the colour panels in Fig. 1 and for the HSS examples in Fig. 5. CNA measurements can be used, together with the ion-chemistry model for the particular location and time, to scale the precipitating electron fluxes to give appropriate instantaneous and local estimates of electron density profiles, assuming only that the shape of the flux-energy spectrum is preserved, while the overall level increases or decreases. In practice, the ionization/ionchemistry model is used to calculate a set of electron density
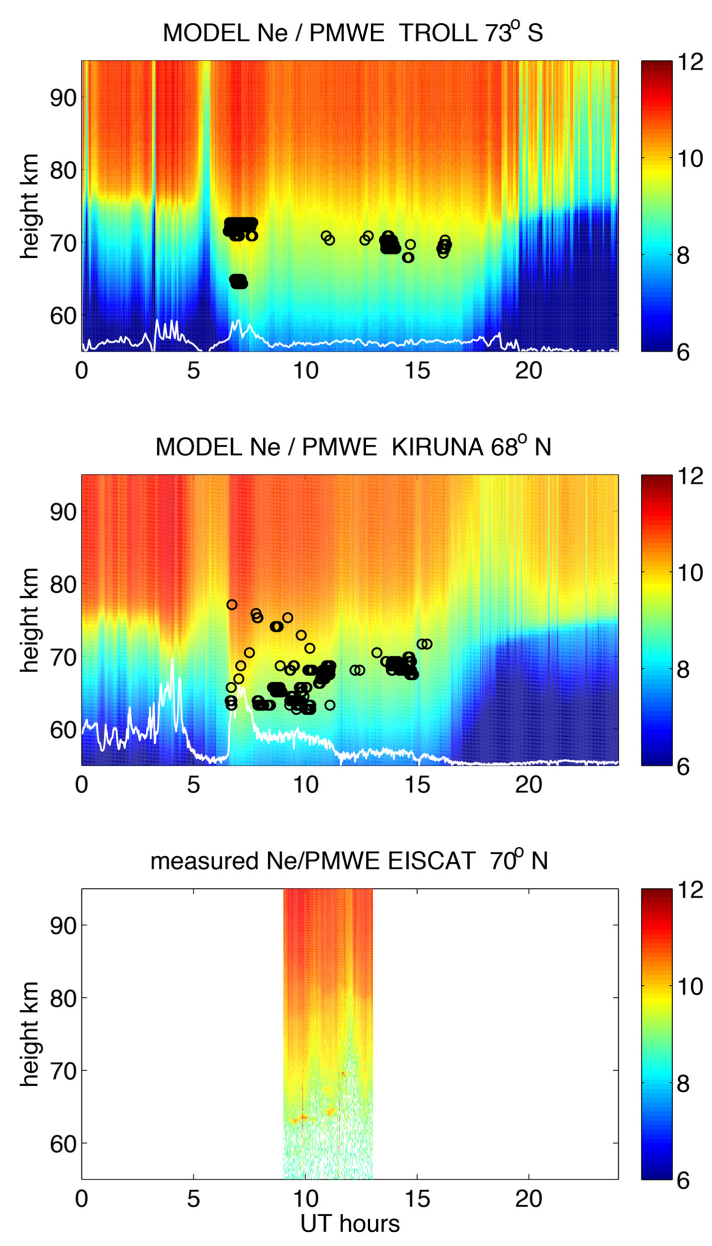

Figure 6. PMWE and CNA observations and modelled and observed electron densities on 21 March 2013. Top panel shows PMWE (black circles) and $54 \mathrm{MHz}$ CNA (white line) observations by the MARA radar in Antarctica, superimposed on modelled electron densities (colour scale). Middle panel shows PWME (black circles) observed by the ESRAD radar in Kiruna, Arctic Sweden, and $38 \mathrm{MHz}$ CNA (white line) observations from a riometer in Kiruna, superimposed on modelled electron densities. In the top two panels, $1 \mathrm{~dB}$ CNA corresponds to $5 \mathrm{~km}$ on the height axis. Bottom panel shows electron density/PMWE measurements by the EISCAT VHF radar, $200 \mathrm{~km}$ north of Kiruna. The narrow yellow/red layer close to 10:00 UT/65 km is PMWE; elsewhere the colour scale shows electron density (scale for electron densities is $\log _{10} \mathrm{~m}^{-3}$ ).

and CNA estimates for several flux levels, for the location and time of interest. The measured CNA is then used to interpolate between the results for the different flux levels. The technique can be applied to any location where CNA measurements are available.

As a demonstration and test of the method of electron density estimation, Fig. 6 shows an example where we have used the "HSS-mean" form of the flux-energy spectrum of precipitating electrons from Table 3, scaled using CNA measured by MARA to estimate the electron densities at Troll, and us- 

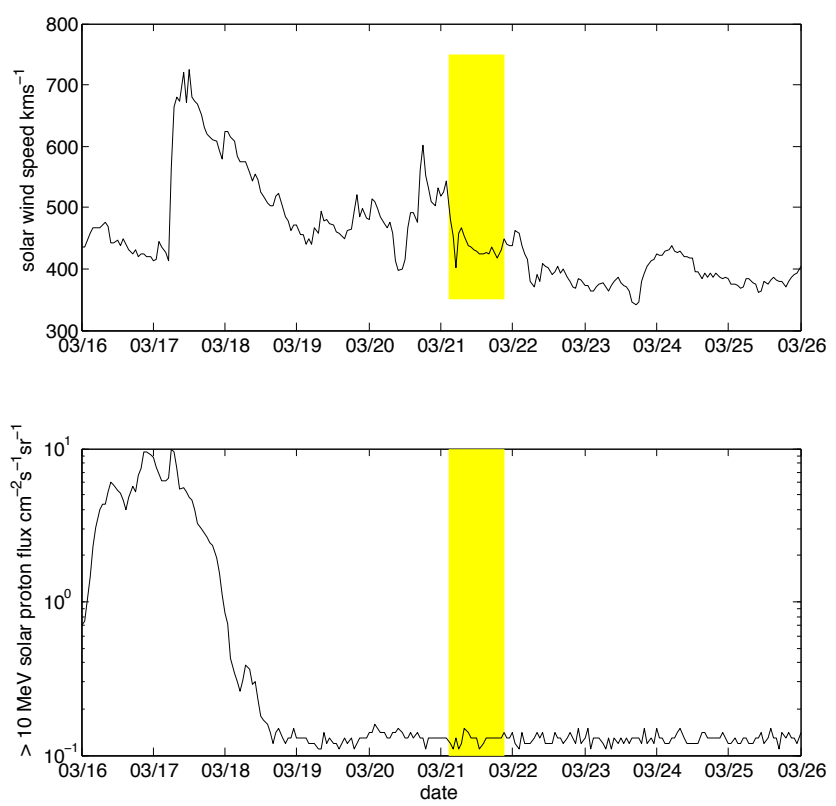

Figure 7. Solar wind speed and flux of $>10 \mathrm{MeV}$ protons from the OMNI 2 data set (http://omniweb.gsfc.nasa.gov/) between 16 and 25 March 2013. The yellow area corresponds to the model/observation period in Fig. 6.

ing CNA measured in Kiruna, Sweden $\left(68^{\circ} \mathrm{N}, 21^{\circ} \mathrm{E} ; 65^{\circ} \mathrm{N}\right.$ geomagnetic), to estimate electron densities for comparison with the nearby EISCAT incoherent-scatter radar site $\left(70^{\circ} \mathrm{N}\right.$, $20^{\circ} \mathrm{E} ; 66^{\circ} \mathrm{N}$ geomagnetic), where, on this occasion, direct observations of electron density were made. PMWE observations by MARA at Troll and by the VHF radar ESRAD in Kiruna are also indicated (black circles). This method is only applicable when the HSS-associated high-energy electron precipitation dominates the CNA response, so we apply it only after the arrival of the HSS. Figure 7 shows that the measurement period occurred 5 days after the arrival of an HSS, and there were no significant fluxes of solar protons. In Fig. 6, as might be expected for HSS-initiated electron precipitation, the behaviour is clearly similar but not exactly synchronous between the Arctic and Antarctic locations - both are at similar geomagnetic latitudes, but Troll is about $3 \mathrm{~h}$ behind Kiruna in magnetic local time. The date of the observations is close to equinox, so the daily variation in the solar illumination is similar at both locations. Both show clear day-night differences below $75 \mathrm{~km}$, where the effects of negative ions strongly reduce electron densities at night, with PWME confined to the intervals of higher electron density during daytime. Finally, Fig. 8 compares height profiles at two time intervals, where different forms of the flux-energy spectrum have been used for the electron density estimate (solid line: HSS-mean; dashed line: HSS-UQ; dotted line: HSS-LQ). Here the differences which come from using different spectral forms can be seen with the HSS-LQ form, which is "harder", i.e. a bigger proportion of electrons
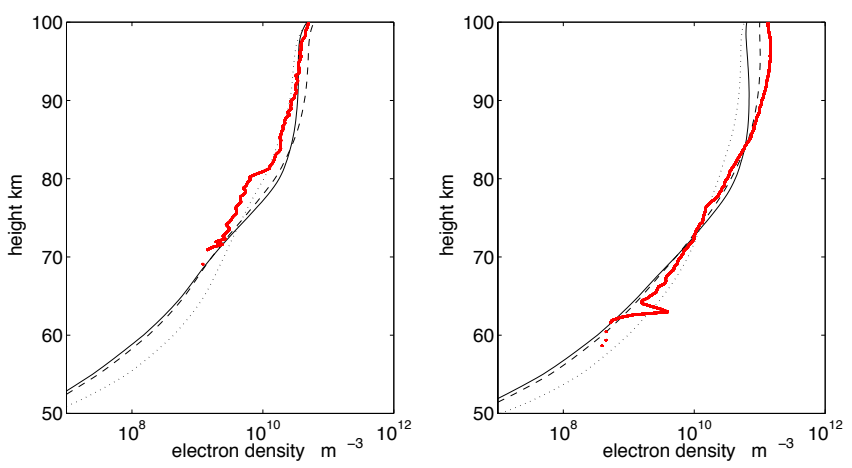

Figure 8. Comparison of modelled and measured electron densities on 21 March 2013; median values at 11:45-12:15 UT (left-hand panel) and 09:15-10:15 UT (right-hand panel). Black lines show model results based on measured CNA and the HSS-mean model (solid lines), the HSS-UQ model (dashed lines) and the HSS-LQ model (dotted lines). HSS models are as defined in Eqs. (1) and (2) and Table 3. Red lines show measurements from the EISCAT VHF radar.

at higher energies, resulting in electron densities which are higher at low altitude and lower at higher altitude compared to the other forms. All spectral forms, however, result in reasonable agreement between the modelled electron densities and the observations at EISCAT (Fig. 8), at least for electron densities above $10^{9} \mathrm{~m}^{-3}$. Unfortunately, EISCAT does not have sufficient sensitivity to measure lower electron densities than this.

Electron density estimates as in Fig. 6 have been computed for all of the 12 HSS events shown in Fig. 5 and Table 2. This comprises 95 days (between 4 and 15 days per event) out of the 453 days of MARA observations between March and October in 2012 and 2013. PWME were detected on 67 of the 95 days. Statistics of the relationship between PMWE occurrence, modelled electron density $\left(N_{\mathrm{e}}\right)$ and solar zenith angle are summarized in Fig. 9. The results are also shown in relation to the modelled ratio of negative ions to electrons $\left(N^{-} / N_{\mathrm{e}}\right)$, as this parameter is also expected to have an influence on the strength of radar echoes (see e.g. Stebel et al., 2004). White areas in the panels in Fig. 9 show $N^{-} / N_{\mathrm{e}}-N_{\mathrm{e}}$ combinations which were not present in the data set, and dark blue areas indicate $N^{-} / N_{\mathrm{e}}-N_{\mathrm{e}}$ combinations which were present, but no PWME were observed in those conditions. The colour scale shows the rate at which PWME were observed in all other conditions. Negative solar zenith angles indicate pre-noon conditions, and positive values indicate post-noon. In darkness (solar zenith angle $>98^{\circ}$ or $\left.<-98^{\circ}\right)$ it is clear that high $N_{\mathrm{e}}\left(>10^{3-4} \mathrm{~cm}^{-3}\right)$ and low $N^{-} / N_{\mathrm{e}}\left(<10^{1} \mathrm{~cm}^{-3}\right)$ allow PWME to appear. Although not apparent from Fig. 9, in practice almost all (92\%) of the PWME observed in darkness were at heights above $70 \mathrm{~km}$. In daytime (solar zenith angle between $-90^{\circ}$ and $+90^{\circ}$ ), PWME were observed in almost all kinds of conditions $\left(N_{\mathrm{e}}>10^{1} \mathrm{~cm}^{-3}\right.$ and $\left.N^{-} / N_{\mathrm{e}}<3 \times 10^{3} \mathrm{~cm}^{-3}\right)$. In twi- 
light (solar zenith between 90 and $98^{\circ}$ ), there was a substantial asymmetry between dawn and dusk, with PWME during dawn being confined to the same $N^{-} / N_{\mathrm{e}}-N_{\mathrm{e}}$ conditions as at night, whereas during dusk, PMWE prevalence was similar to daytime.

\section{Discussion}

Our results show that PWME are detected by MARA in conditions when ionization rates are increased by the precipitation of high-energy electrons from the radiation belts, which is triggered by the arrival of high-speed solar wind streams. In order for PWME to be detected by the radar, they have to be strong enough to exceed the noise level of the measurements. Several factors affect the strength of any radar echo from the mesosphere. Basically there must be fluctuations in the vertical profile of radar refractive index with a component at half the radar wavelength, i.e. $3 \mathrm{~m}$ scale size for a $50 \mathrm{MHz}$ radar. Free electrons are the major contributor to refractive index at mesospheric heights, so this means that $3 \mathrm{~m}$ scale fluctuations in electron density are needed. Precipitating high-energy electrons provide only a relatively smoothly varying height profile of electron density, and three different processes have been suggested which can lead to fluctuations at $3 \mathrm{~m}$ scale - turbulence in the neutral gas, acoustic waves and dust/aerosol layers. In the first two cases, fluctuations in neutral density are passed on to the ions present by collisions, and any free electrons are constrained to follow fluctuations in ion density to maintain charge balance. Dust/aerosol layers, on the other hand, can be electrically charged, passing on charge density variations, both small-scale fluctuations and sharp vertical gradients, directly to the electron gas (again to maintain charge balance).

In the case of neutral turbulence caused by wind shear, the theory of the relationship between radar volume reflectivity and turbulence and plasma parameters is well developed. For example, following the work of Hill (1978), Hill et al. (1999) and Hocking (1985), it can be shown that volume reflectivity depends on the atmospheric density, temperature, turbulent energy dissipation rate, the ratio of free electrons to negative ions, and the square of the electron density and electron density gradient (a detailed derivation and discussion can be found in Stebel et al., 2004). In order to further interpret the relationships we have found between PWME and $N^{-} / N_{\mathrm{e}}$ and $N_{\mathrm{e}}$ in our observations, it is useful to compare our observations with theoretical predictions made on the basis of this turbulence theory. Our electron density/ionchemistry model, together with the underlying neutral atmosphere model MSISO0E (Hedin, 1991), provides all necessary input parameters except the level of turbulence and the buoyancy frequency. For the turbulent energy dissipation rate we assume $100 \mathrm{~mW} \mathrm{~kg}^{-1}$, which is at the upper end of values observed in the winter high-latitude mesosphere (e.g. Lübken, 1997). For buoyancy frequency we adopt a typical value of $0.02 \mathrm{rad} \mathrm{s}^{-1}$. Results are shown in Figs. 10 and 11. It is immediately obvious that theoretical predictions of PMWE volume reflectivity based on the turbulence theory are several orders of magnitude less than those observed, except for the highest electron densities (Fig. 10), which correspond to the highest PMWE heights (Fig. 11), above $75 \mathrm{~km}$, where PWME are present only in twilight or during the night. The strong dependence of volume reflectivity on $N^{-} / N_{\mathrm{e}}$ and $N_{\mathrm{e}}$, which is predicted by the theory, is simply not observed for the daytime PWME. If the theoretical predictions in the upper panels of Figs. 10 and 11 were correct, PWME would be detected only where the theoretical predictions are plotted as orange or red.

It is possible that the theoretical predictions could be underestimated due to the possibility of a harder energy-flux spectrum (HSS-LQ rather than HSS-mean), as well as underestimates of the CNA (standard deviation 0.07 dB). However, calculations using the HSS-LQ spectral form, and increasing CNA values by $0.07 \mathrm{~dB}$ (not shown), result in increases in predicted volume reflectivity which are relatively small - about $20 \%$ for $\eta>10^{-16}$, increasing to a factor of 4 at $\eta>10^{-17}$ and a factor of 10 at $\eta>10^{-19}$. This could bring PWME to detectable levels, where the theoretical volume reflectivities in the upper panels of Figs. 10 and 11 are shown as yellow, as well as orange or red. But this is not enough to remove the several-orders-of-magnitude discrepancy between theory and observation at high $N^{-} / N_{\mathrm{e}}$ and low $N_{\mathrm{e}}$.

The lack of sensitivity to $N^{-} / N_{\mathrm{e}}$ and $N_{\mathrm{e}}$ in the observations shown by Fig. 10 illustrates well that PWME are likely not due to neutral turbulence alone. If PWME were caused solely by damped ion-acoustic waves as suggested in Kirkwood et al. (2006), we would expect their strength to be strongly dependent on the electron density and the negative ion/electron ratio, in the same way as for turbulence theory. Apart from the lack of $N^{-} / N_{\mathrm{e}}$ and $N_{\mathrm{e}}$ dependence, there is also a problem in explaining the asymmetry between dawn and dusk shown in Fig. 9, the absence of PWME above $75 \mathrm{~km}$ during the day, or the almost complete absence of radar echoes below $80 \mathrm{~km}$ altitude during summer. There is nothing in turbulence/ion-acoustic wave theory which could comfortably explain all of these features.

A possible explanation is the presence of charged dust or other aerosol particles, together with turbulence or acoustic waves. Modelling work by Megner et al. (2008) and Bardeen et al. (2008) suggests that substantial amounts of meteoric smoke particles (MSP) accumulate in the high-latitude winter mesosphere (concentrations of several thousand per cubic centimetre). The MSP are transported from upper mesosphere heights over the whole globe and downward into the lower polar winter mesosphere by global-scale wind systems. In summer, in contrast, upward motion effectively empties the lower polar mesosphere of MSP. More recent satellite extinction measurements support these model predictions (Hervig et al., 2009). Sounding-rocket measurements at Arc- 

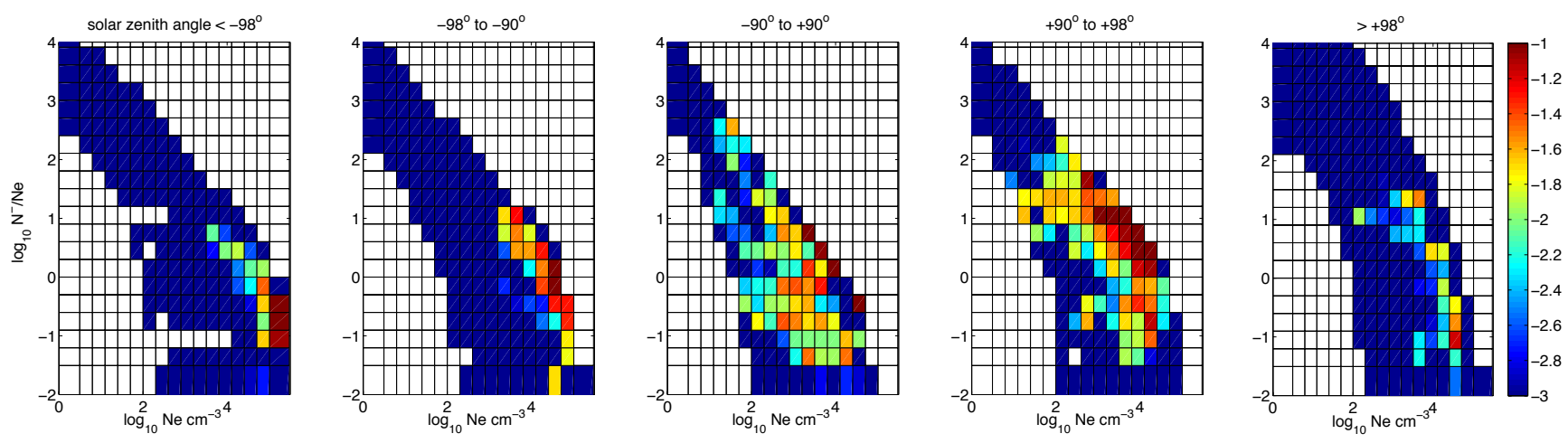

Figure 9. PMWE detection rates at heights of $50-80 \mathrm{~km}$, as a function of modelled electron density and modelled ratio of negative ion to electron density: (first panel) morning darkness, (second panel) morning twilight, (third panel) daylight, (fourth panel) evening twilight, and (fifth panel) evening darkness. Colour scale is $\log _{10}$ of the PMWE detection rate. White areas indicate conditions not present at any time during the modelled events.
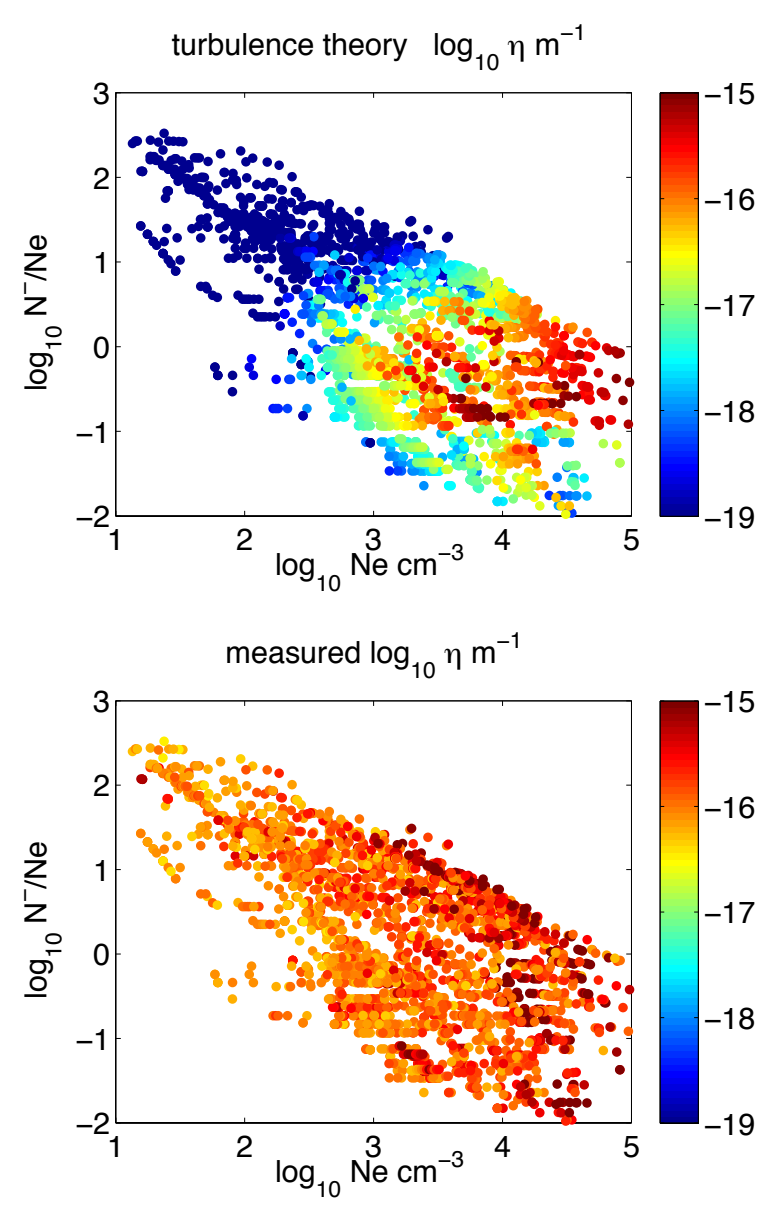

Figure 10. Theoretically expected and observed PMWE volume reflectivities as a function of modelled electron density and modelled ratio of negative ion to electron density. Theoretical estimates are for turbulence due to wind shear assuming a turbulent energy dissipation rate of $100 \mathrm{~mW} \mathrm{~kg}^{-1}$ and buoyancy frequency of $0.02 \mathrm{rad} \mathrm{s}^{-1}$.

tic latitudes have found evidence for the presence of significant amounts of charged MSP - concentrations during up to $3000 \mathrm{~cm}^{-3}$ during night-time and $300 \mathrm{~cm}^{-3}$ during daytime have been found (e.g. Robertson et al., 2014). The effect of charged aerosol in the mesosphere on radar reflectivity was examined theoretically by Varney et al. (2011). Although the latter paper was primarily concerned with PMSE rather than PWME, the theoretical expressions are applicable to both. The most important results are that radar volume reflectivity can be expected to be substantially enhanced by the presence of positively or negatively charged MSP, and that the reflectivity increases with increasing $N_{\mathrm{e}}$ only when $N_{\mathrm{e}}$ is much less than the density of charged dust. Otherwise, the charged dust density and particle size are the main controlling factors for the reflectivity (together with turbulence and background neutral atmosphere conditions).

The most directly relevant in situ observations for our present study are those made by two sounding rockets launched from Arctic Norway reported by Robertson et al. (2014). One rocket was launched during night-time and one during daytime, on 11 and 13 October 2011, respectively. Although not mentioned in Robertson et al. (2014), both launches were after the arrival of an HSS and the ESRAD radar, $240 \mathrm{~km}$ south-west of the launch site, observed PWME during daytime on the 12 and 13 October, so conditions were relevant for our study. Robertson et al. (2014) found distinct differences for heights below about $75 \mathrm{~km}$ and above that height. Above about $75 \mathrm{~km}$, no positive MSP were detected and negative MSP were present with densities up to $300 \mathrm{~cm}^{-3}$ at night but only about $100 \mathrm{~cm}^{-3}$ during daytime. Below $75 \mathrm{~km}$, negative and positive MSP were present in approximately equal large numbers up to $3000 \mathrm{~cm}^{-3}$ at night but were much less abundant and in unequal numbers during the day, with at least an order of magnitude more positive MSP (up to $300 \mathrm{~cm}^{-3}$ ) than negative MSP.

Careful examination of the distribution of PWME in Fig. 11 indicates a similar difference in behaviour above and 

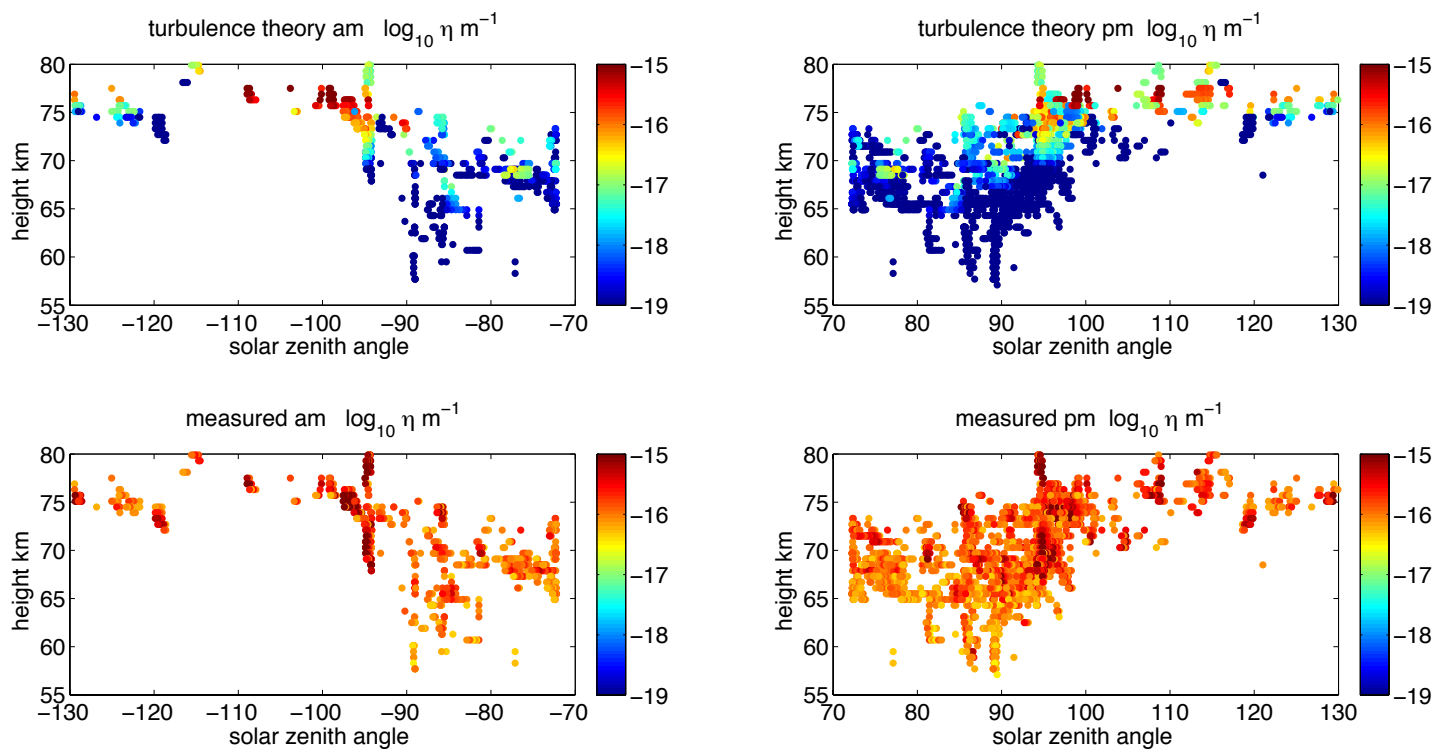

Figure 11. Theoretically expected and observed PMWE volume reflectivities as a function of solar zenith angle and height. Theoretical estimates are for turbulence due to wind shear assuming a turbulent energy dissipation rate of $100 \mathrm{~mW} \mathrm{~kg}^{-1}$ and buoyancy frequency of $0.02 \mathrm{rad} \mathrm{s}^{-1}$.

below about $75 \mathrm{~km}$ altitude. Above $75 \mathrm{~km}$, PWME are seen during the night or twilight but rarely during the day. Below $75 \mathrm{~km}$, the opposite holds - PWME are seen only during the day or twilight, and not at night. This suggests that PWME above $75 \mathrm{~km}$ are caused by negative MSP, with the absence of PWME above $75 \mathrm{~km}$ during the day due to smaller numbers of negative MSP in the daytime. PWME below $75 \mathrm{~km}$ would then correspond to positive MSP. The absence of PWME below $75 \mathrm{~km}$ at night might be explained by electron scavenging by the MSP, which can deplete the electron density to very low levels, even below those due to night-time (molecular) negative-ion formation (e.g. Friedrich et al., 2012; Baumann et al., 2013; Robertson et al., 2014). Above $75 \mathrm{~km}$ at night, (molecular) negative ions are not as important, so electron density can remain at higher levels. During daytime, negatively charged MSP are likely to be discharged by photoemission. This, together with the absence of (molecular) negative ions, allows electron density to remain high, and the availability of positive MSP (below $75 \mathrm{~km}$ ) will lead to strong PWME. Depending on the time constants of the processes controlling changeovers from night to day and day to night conditions, an explanation might be found for the asymmetry of PWME between dawn and dusk, but so far those time constants are not known.

Altogether, consideration of the possible role of MSP can explain several aspects of the observed PMWE behaviour. The strong seasonality of MSP offers an immediate explanation for the seasonality of PWME. Thin layers have been observed in the charged dust (e.g. Robertson et al., 2014), which could explain the layered appearance of PWME (in addition to the layered nature of turbulence or acoustic sources). The apparent lack of sensitivity to $N_{\mathrm{e}}$ during daytime can be explained by $N_{\mathrm{e}}$ higher than charged MSP concentrations. The contrasting day-night differences above and below $75 \mathrm{~km}$ height can be explained by differences in MSP number densities and electron scavenging below $75 \mathrm{~km}$ by both MSP and negative ions at night. There is, however, no clear explanation for the lack of PWME above $80 \mathrm{~km}$ height. Some observations suggest maximum concentrations of charged MSP at about $85 \mathrm{~km}$ (e.g. Friedrich et al., 2012), although direct night-time observations show a sharp reduction above $80 \mathrm{~km}$ (Robertson et al., 2014). Model results suggest that only the smaller MSP $(<5 \mathrm{~nm}$ radius) should be present above $80 \mathrm{~km}$ height (Megner et al., 2008), which would also reduce the radar reflectivity.

Although we have found a lack of PMWE sensitivity to $N_{\mathrm{e}}$ during daytime, there is quite clearly a sensitivity to disturbed conditions since PWME appear preferentially in the days following the arrival of HSS. It is possible that this is due to changes in dust charging rather than the (sometimes very small) increase in electron density due to precipitating electrons. This would apply if the lifetime of dust charge is much longer than the ion-electron/ion-ion recombination times. Dust charging and recombination might also be influenced by changes in neutral chemistry (e.g. $\mathrm{NO}_{x}$ ) which are caused by energetic electron precipitation.

\section{Conclusions}

A small $54 \mathrm{MHz}$ wind-profiler radar, MARA, operated during two complete Antarctic winters in 2012 and 2013 at Troll, Antarctica $\left(72^{\circ} \mathrm{S}, 2.5^{\circ} \mathrm{E} ; 63^{\circ} \mathrm{S}\right.$ geomagnetic). PWME, at 
heights of $55-80 \mathrm{~km}$, were observed on $60 \%$ of all winter days (from March to October). Above $75 \mathrm{~km}$ height, PWME appear at night and during twilight. Below $75 \mathrm{~km}$ they appear only during daytime or evening twilight. We find a close correlation between the onset of PWME and the arrival of HSS. PWME appear at heights as low as $56 \mathrm{~km}$ immediately following the HSS arrival, clearly demonstrating direct effects of the HSS at those heights. Once initiated, PWME appear on consecutive days for up to 15 days, which is 7 days longer than it has so far been reported that HSS effects on energetic electron precipitation persist, on the basis of satellite instruments (e.g. Meredith et al., 2011). The persistence of energetic electron precipitation after HSS arrival, including during times when $\mathrm{Kp}$ and solar wind speed fall back to low levels, can explain at least part of the $44 \%$ occurrence rate of PWME even in the absence of enhanced Kp, solar wind speed, proton flux or X-ray flux (Table 1, row 1).

A model of ionization profiles due to typical energetic electron precipitation during HSS is used together with local observations of CNA to estimate the electron density and ion-chemistry conditions during PWME. If PWME were due to irregularities in neutral density caused by turbulence or acoustic waves (without charged aerosol), a strong dependence of PMWE volume reflectivity on electron density and the ratio of negative ion to electron density would be expected. This is not observed.

Consideration of observed characteristics of charged dust particles in the winter mesosphere shows that this is a reasonable candidate to explain many of the climatological characteristics of PWME. In this case, PWME above $75 \mathrm{~km}$ are enhanced by negatively charged dust. The absence of PWME above $75 \mathrm{~km}$ during the day may be due to reduction in the amount of negative dust by photoelectric emission. PWME below $75 \mathrm{~km}$ are likely enhanced by positively charged dust. Below $75 \mathrm{~km}$ at night, electrons are likely scavenged by both dust and negative ions, leading to too low electron density for detectable PWME. The appearance of PWME following the arrival of HSS may be due to changes in dust charging as a result of energetic electron precipitation.

Further observations of PWME, including comparison of characteristics between the Arctic and Antarctica, particularly with more sensitive radars, offer the possibility of tracking dust climatology and thus understanding more about the global circulation in the mesosphere.

The observations of PWME presented here clearly demonstrate the direct penetration of effects from HSS down to $55 \mathrm{~km}$ height or lower in the polar regions. Earlier publications have shown PWME resulting from solar proton precipitation. Once the role of dust is better understood, PWME can easily be used to track year-to-year variability in the prevalence of HSS and solar proton influence on this part of the atmosphere.
Acknowledgements. Measurements with MARA at Troll were supported by Swedish Polar Research Secretariat and Norwegian Polar Institute. This research was partly funded by the Swedish Research Council (grant 621-2010-3218) and the Knut and Alice Wallenberg Foundation, Sweden. EISCAT is an international association supported by research organizations in China (CRIRP), Finland (SA), Japan (NIPR and STEL), Norway (NFR), Sweden (VR) and the United Kingdom (NERC).

The topical editor C. Jacobi thanks two anonymous referees for help in evaluating this paper.

\section{References}

Barabash, V., Osepian, A., Dalin, P., and Kirkwood, S.: Electron density profiles in the quiet lower ionosphere based on the results of modeling and experimental data, Ann. Geophys., 30, 13451360, doi:10.5194/angeo-30-1345-2012, 2012.

Bardeen, C. G., Toon, O. B., Jensen, E. J., Marsh, D. R., and Harvey, V. L.: Numerical simulations of the three-dimensional distribution of meteoric dust in the mesosphere and upper stratosphere, J. Geophys. Res., 113, D17202, doi:10.1029/2007JD009515, 2008.

Baumann, C., Rapp, M., Kero, A., and Enell, C.-F.: Meteor smoke influences on the D-region charge balance - review of recent in situ measurements and one-dimensional model results, Ann. Geophys., 31, 2049-2062, doi:10.5194/angeo-31-20492013, 2013.

Belova, E., Kirkwood, S., Ekeberg, J., Osepian, A., Haggstrom, I., Nilsson, H., and Rietveld, M.: The dynamical background of polar mesosphere winter echoes from simultaneous EISCAT and ESRAD observations, Ann. Geophys., 23, 1239-1247, 2005, http://www.ann-geophys.net/23/1239/2005/.

Belova, E., Smirnova, M., Rietveld, M. T., Isham, B., Kirkwood, S., and Sergienko, T.: First observation of the overshoot effect for polar mesosphere winter echoes during radiowave electron temperature modulation, Geophys. Res. Lett., 35, L03110, doi:10.1029/2007GL032457, 2008.

Ecklund, W. L. and Balsley, B. B.: Long-term observations of the arctic mesosphere with the MST radar at Poker Flat, Alaska, J. Geophys. Res., 86, 6722-6734, 1981.

Friedrich, M., Rapp, M., Blix, T., Hoppe, U.-P., Torkar, K., Robertson, S., Dickson, S., and Lynch, K.: Electron loss and meteoric dust in the mesosphere, Ann. Geophys., 30, 1495-1501, doi:10.5194/angeo-30-1495-2012, 2012.

Hedin, A. E.: Extension of the MSIS thermosphere model into the middle and lower atmosphere, J. Geophys. Res., 96, 1159-1172, 1991.

Hervig, M. E., Gordley, L. L., Deaver, L. E., Siskind, D. E., Stevens, M. H., Russell, J. M., Bailey, S. M., Megner, L., and Bardeen, C. G.: First Satellite Observations of Meteoric Smoke in the Middle Atmosphere, Geophys. Res. Lett., 36, 18805-18810, doi:10.1029/2009GL039737, 2009.

Hill, R.: Nonneutral and quasi-neutral diffusion of weakly ionized multiconstituent plasma, J. Geophys. Res., 83, 989-998, 1978. 
Hill, R., Gibson-Wilde, D., and Werne, J. A., and Fritts, D.: Turbulent induced fluctuations in ionisation and application to PMSE, Earth Planets Space, 41, 499-513, 1999.

Hocking, W. K.: Measurement of turbulent energy dissipation rates in the middle atmosphere by radar techniques: A review, Radio Sci., 20, 1403-1422, doi:10.1029/RS020i006p01403, 1985.

Kashirin, A. I.: Photoionization of the nightime ionosphere, Geomagn. Aeron., 26, 563-568, 1986.

Kavanagh, A. J., Honary, F., Donovan, E. F., Ulich, T., and Denton, M. H.: Key features of $>30 \mathrm{keV}$ electron precipitation during high speed solar wind streams: A superposed epoch analysis, J. Geophys. Res., 117, A00L09, doi:10.1029/2011JA017320, 2012.

Kirkwood, S. and Osepian, A.: Quantitative studies of energetic particle precipitation using incoherent-scatter radar, J. Geomag. Geoelec., 47, 783-799, 1995.

Kirkwood, S., Barabash, V., Belova, E., Nilsson, H., Rao, T. N., Stebel, K., Osepian, A., and Chilson, P. B.: Polar mesosphere winter echoes during solar proton events, Adv. Polar Upper Atmos. Res., 16, 111-125, 2002.

Kirkwood, S., Belova, E., Satheesan, K., Narayana Rao, T., Rajendra Prasad, T., and Satheesh Kumar, S.: Fresnel scatter revisited - comparison of $50 \mathrm{MHz}$ radar and radiosondes in the Arctic, the Tropics and Antarctica, Ann. Geophys., 28, 1993-2005, doi:10.5194/angeo-28-1993-2010, 2010.

Kirkwood, S., Belova, E., Dalin, P., Mihalikova, M., Mikhaylova, D., Murtagh, D., Nilsson, H., Satheesan, K., Urban, J., and Wolf, I.: Response of polar mesosphere summer echoes to geomagnetic disturbances in the Southern and Northern Hemispheres: the importance of nitric oxide, Ann. Geophys., 31, 333-347, doi:10.5194/angeo-31-333-2013, 2013.

Kirkwood, S., Osepian, A., Belova, E., Urban, J., Pérot, K., and Sinha, A. K.: Ionization and NO production in the polar mesosphere during high-speed solar wind streams: model validation and comparison with NO enhancements observed by Odin-SMR, Ann. Geophys., 33, 561-572, doi:10.5194/angeo-33-561-2015, 2015.

Kirkwood, S., Osepian, A., and Smirnova, N.: Quantitative description of electron precipitation during auroral absorption events in the morning/noon local-time sector, J. Atmos. Sol. Terr. Phys., 63, 1907-1921, 2001.

Kirkwood, S., Chilson, P., Belova, E., Dalin, P., Haggstrom, I., Rietveld, M., and Singer, W.: Infrasound - the cause of strong Polar Mesosphere Winter Echoes?, Ann. Geophys., 24, 475-491, 2006, http://www.ann-geophys.net/24/475/2006/.

Kirkwood, S., Wolf, I., Nilsson, H., Dalin, P., Mikhaylova, D., and Belova, E.: Polar mesosphere summer echoes at Wasa, Antarctica $\left(73^{\circ} \mathrm{S}\right)$ : First observations and comparison with $68^{\circ} \mathrm{N}$, Geophys. Res. Lett., 34, L15803, doi:10.1029/2007GL030516, 2007.

La Hoz, C. and Havnes, O.: Artificial modification of polar mesospheric winter echoes with an RF heater: Do charged dust particles play an active role?, J. Geophys. Res., 113, D19205, doi:10.1029/2008JD010460, 2008.

Lee, Y.-S., Kirkwood, S., Shepherd, G., Kwak, Y.-S., and Kim, K.-C.: Long-periodic strong radar echoes in the summer polar D region correlated with oscillations of high-speed solar wind streams, Geophys. Res. Lett., 40, 4160-4164, doi:10.1002/grl.50821, 2013.
Lee, Y.-S., Kirkwood, S., Kwak, Y.-S., Kim, K.-C., and Shepherd, G.: Polar summer mesospheric extreme horizontal drift speeds during interplanetary corotating interaction regions (CIRs) and high-speed solar wind streams: coupling between the solar wind and the mesosphere, J. Geophys. Res., 119, 3883-3894, doi:10.1002/2014JA019790, 2014.

Lübken, F.-J., Strelnikov, B., Rapp, M., Singer, W., Latteck, R., Brattli, A., Hoppe, U.-P., and Friedrich, M.: The thermal and dynamical state of the atmosphere during polar mesosphere winter echoes, Atmos. Chem. Phys., 6, 13-24, doi:10.5194/acp-6-132006, 2006.

Lübken, F.-J.: Seasonal variation of turbulent energy dissipation rates at high latitudes as determined by in situ measurements of neutral density fluctuations, J. Geophys. Res., 102, 1344113456, 1997.

Megner, L., Siskind, D. E., Rapp, M., and Gumbel, J.: Global and temporal distribution of meteoric smoke: A twodimensional simulation study, J. Geophys. Res., 113, D03202, doi:10.1029/2007JD009054, 2008.

Meredith, N. P., Horne, R. B., Lam, M. M., Denton, M. H., Borovsky, J. E., and Green, J. C.: Energetic electron precipitation during high-speed solar wind stream driven storms, J. Geophys. Res., 116, A05223, doi:10.1029/2010JA016293, 2011.

Morris, R. J., Klekociuk, A. R., and Holdsworth, D. A.: First observations of Southern Hemisphere polar mesosphere winter echoes including conjugate occurrences at $69^{\circ} \mathrm{S}$ latitude, Geophys. Res. Lett., 38, L03811, doi:10.1029/2010GL046298, 2011.

Rapp, M., Latteck, R., Stober, G., Hoffmann, P., Singer, W., and Zecha, M.: First three-dimensional observations of polar mesosphere winter echoes: Resolving space-time ambiguity, J. Geophys. Res., 116, A11307, doi:10.1029/2011JA016858, 2011.

Rees, M. H.: Auroral ionisation and excitation by incident energetic electrons, Planet. Space Sci., 11, 1209-1218, 1963.

Robertson, S., Dicksom, S., Horanyi, M., Sternovsky, Z., Friedrich, M., Janches, D., Megner, L., and Williams, B.: Detection of meteoric smoke particles in the mesosphere by a rocket-borne mass spectrometer, J. Atmos. Sol. Terr. Phys., 118, 161-179, 2014.

Rodger, C. J., Kavanagh, A. J., Clilverd, M. A., and Marple, S. R.: Comparison between POES energetic electron precipitation observations and riometer absorptions: Implications for determining true precipitation fluxes, J. Geophys. Res. Space Physics, 118, 7810-7821, doi:10.1002/2013JA019439, 2013.

Smirnova, N., Ogloblina, O., and Vlaskov, V.: Modelling of the lower ionosphere, Pageophys., 127, 353-379, 1988.

Stebel, K., Blum, U., Fricke, K., Kirkwood, S., Mitchell, N., and Osepian, A.: Joint radar/lidar observations of possible aerosol layers in the winter mesosphere, J. Atmos. Sol. Terr. Phys., 66, 957-970, doi:10.1016/j.jastp.2004.03.008, 2004.

Torkar, K. M. and Friedrich, M.: Tests of an ion-chemical model in the D and lower E region, J. Atmos. Terr. Phys., 35, 369-385, 1983.

Tsurutani, B., Gonzalez, W., Gonzalez, A., Guarnieri, F., Gopalswamy, N., Grande, M., Kamide, Y., Kasahara, Y., Lu, G., Mann, I., McPherron, R., Soraas, F., and Vasilyunas, V.: Corotating solar wind streams and recurrent geomagnetic activity : A review, J. Geophys. Res., 111, A07S01, doi:10.1029/2005JA011273, 2006. 
Varney, R. H., Kelley, M. C., Nicolls, M. J., Heinselman, C. J., and Collins, R. L.: The electron density dependence of polar mesospheric summer echoes, J. Atmos. Sol.-Terr. Phy., 73, 21532165, doi:10.1016/j.jastp.2010.07.020, 2011.
Zeller, O., Zecha, M., Bremer, J., Latteck, R., and Singer, W.: Mean characteristics of mesospheric winter echoes at midand high-latitudes, J. Atmos. Sol. Terr. Phys., 68, 1087-1104, doi:10.1016/j.jastp.2006.02.015, 2006. 